\title{
Application of the Thin Slice Model for Determination of Face Load Distribution along the Line of Contact and the Relative Load Distribution Measured along Gear Root
}

\author{
Wiktor Kamycki* - Stanisław Noga \\ Rzeszów University of Technology, Faculty of Mechanical Engineering and Aeronautics, Poland
}

This article concerns the investigation of the relationship between stress distribution caused by contact during tooth flank engagement and tensile stress distribution due to bending at the tooth root. Four different approaches are discussed. The first refers to ISO 6336 guidelines describing the relationship with a simple empirical formula. The second is the proposed thin slice model developed in MATLAB computer software. The third approach is based on finite element analysis (FEA). The last experimental method uses a bespoke test rig designed and manufactured for this work. The thin slice model has been verified against ISO 6336 guidelines, FEA simulation, and the test rig measurements. Two phenomena have been observed: coupling and edge effect, both of which impact the relationship between load intensity distribution for contact and bending.

Keywords: gear, load distribution, face load factor, stress distribution, strain gauging

\author{
Highlights \\ - A thin slice model for conversion between face load distributions has been developed. \\ - $\quad$ FEA has been performed and a bespoke test rig manufactured as a point of reference. \\ - The coupling effect follows ISO 6336 prescriptions. \\ - $\quad$ Gear tooth edge compliance noted in FEA and test rig measurements.
}

\section{INTRODUCTION}

Gears are integral elements of machines and car drivetrain systems. Every mechanism, including transmissions, is fraught with errors, which must be taken into account in the design stage. The most common deviation regarding gearboxes is gear misalignment causing non-uniform load distribution along the gear face width. A crucial point in the design process relates to the need to determine face load distribution for contact and root stress.

Face load factors $K_{F \beta}$ and $K_{H \beta}$ have a direct impact on gear durability. Non-uniform distribution of transmitted load leads to stress concentration in specific regions of teeth, making them prone to failures. According to ISO 6336 [1] to [3], the two face load factors $K_{F \beta}$ and $K_{H \beta}$ directly affect the maximum permissible load (regarding contact and bending stress) that the gear teeth transmit. The constantly growing power density of gearboxes and the continued requirement to improve their reliability call for accurate determination of the above factors, ideally using method A prescribed in ISO 6336-1 [1] (measurements by root strain gauging). Strain measurements across the gear roots allow the determination of the relative root bending stress distribution factor $K_{F \beta}$. However, direct measurements of the face load factor for contact stress
$K_{H \beta}$ are presently not possible; to derive this factor, an additional conversion is required, based on the gear geometry and known face load factor $K_{F \beta}$ [1].

The relationship between relative stress intensity distribution across gear root and gear flank forms the basis of gear strength calculations. The possibility of converting between face load distribution and measured root stress distribution enables the calculation of the maximum permissible load transferred by a gearbox. Despite certain guidelines and empirical relationships found in ISO standards, the available information does not provide a thorough understanding of the correlation between the factors. This research discusses the correlation between the face load factors as recommended in ISO 6336-1 standard [1].

The relationship between the face load factors has not been extensively examined. However, much work has been done on the investigation of the load distribution factors separately. An influence of shaft misalignment on the contact stress status has been proved in [4], investigating load distribution along the tooth profile and along the tooth width. Additionally, a model of the gear system was developed using finite element analysis (FEA), based on dividing the system into a number of substructures. Gear mesh stiffness has been analysed by Chang et al. [5], dividing the deformation of a tooth into global and local contact 
terms. The effect of contact ratio has been examined, and parameters influential on mesh stiffness have been identified. Various misalignment modes have been simulated by Lias et al. [6], using different contact load arrangements and investigating their influence on root bending stress distribution. In [7] and [8], the authors compared methods for determining the gear teeth load capacity using ISO, AGMA standards, and FEA. The accuracy of the geometry of cylindrical spur gear teeth was analysed in [9]. The authors designed and manufactured the gears with the direct metal laser sintering method, sand-blasted, ground and measured on a coordinate measuring machine after each manufacturing step. Zeng et al. [10] and [11] aimed to simulate straight bevel gear [10] and spur gear [11] transmission by deducing the equations for the tooth surface, tooth root surface, and toothroot transition surface. The equations led to create 3D assembly model of gear pairs and simulate in ANSYS software. The proposed modelling method is claimed to be more accurate than the traditional modelling method, especially in terms of contact and root bending stress values. In [12] and [13], the authors discuss proposed algorithms for teeth contact analysis under load, focused on determining the load distribution, including manufacturing and shaft seating errors. In [14] and [15], the authors propose methods for gear transmission error evaluation used for gear mesh analyses. Other research [16] estimated the impact of the method used to determine the face load factors on the results of gearing calculations. Wang et al. [17] developed the thin slice model in which the time-varying mesh stiffness of a helical gear was examined. The thin slice model was used for the calculation of transverse tooth stiffness. In addition, they took into consideration transverse gear foundation stiffness, axial mesh stiffness and Hertzian contact stiffness. The authors compared time-varying mesh stiffness of the developed analytical model and FEA, distinguishing transverse and axial stiffness. Gear root stress distribution was tested against various load conditions and lead to modifications by Haigh and Fawcett [18] as a part of a programme of experimental work carried out using an $8 \mathrm{MW}$ facility for gear noise and vibration at the University of Newcastle upon Tyne. Pedrero et al. [19] presented a model of non-uniform load distribution along the line of contact for spur and helical gear teeth. The analytical model was obtained from the minimum elastic potential energy criterion and validated against FEA, yielding similar results. The authors present an approximate equation for the inverse unitary potential expressed as a function of transverse contact ratio.
The equation allows the evaluation of the contact and bending stresses. Guilbaut et al. [20] have developed an express model for the analysis of load sharing, fillet and contact stresses. The model uses the fine-strip method combined with a pseudo-three-dimensional (3D) model of a tooth base as an alternative to FEA. Ajmi and Velex [21] proposed a theory covering tooth contact characteristics and dynamic calculations. The developed theory of gear mesh stiffness includes gear body stiffness, tooth deflections, and contact stiffness. An experimental study [22] was made, with the use of strain gauged gears, observing the significant influence of gear misalignment and the amount of lead crown on maximum root and contact stress values, as well as root stress distribution. Another work [23] focuses on lead crown optimisation to reduce maximum contact and root stress values. The authors have successfully developed a method of lead crown modification that was based on FEA simulations.

Most of the work focuses on gear calculation methods to verify its parameters for load capacity. However, there is a lack of published research results on the relationship between the $K_{F \beta}$ and $K_{H \beta}$ factors. Knowledge of this relationship would allow drawing conclusions about the load distribution along the contact line only based on the load distribution at the root of the tooth, which can be measured under real conditions. An attempt was made [24] in which the authors determined the load distribution along the contact line based on circumferential tooth deformation measurements. These types of measurements can only be carried out at a test rig under conditions that do not correspond to actual operating conditions. A correlation between root strain measurements and the $K_{H \beta}$ has been analysed in [25]. A bottom-up approach was presented based on gear tooth stiffness calculations, in which signal from the strain gauges is transformed to the load on the tooth flank by means of a tooth stiffness model. The stiffness values were derived from dedicated FEA. The model consists of functions that express the relationship between strain gauge signal and applied force located at a point, perpendicular to the tooth flank. The author claims that when several forces are applied on the tooth flank, the resulting strain gauge signal is a superposition of the strain signals induced by the individual forces. The analysis required experimental verification of the predicted load distribution on the tooth flank adjusting the gear misalignment.

This work constitutes the development of a master's thesis [26], which was written with support from the company Transmission Dynamics Ltd. The approach presented in this paper has been verified by 
the authors [27] against ISO 6336 guidelines, in which the correlation between the face load factors $K_{F \beta}$ and $K_{H \beta}$ was analysed in relation to gear face width and unevenness of the load applied.

This research aims to develop an algorithm to investigate the relationship between face load factors $K_{F \beta}$ and $K_{H \beta}$, which take into account the effect of load distribution over the face width for bending stress and contact stress, respectively. To achieve the above aims, the following objectives have been accomplished:

- guidelines available in ISO 6336-1 concerning the determination of face load factors have been examined,

- an original tool using MATLAB software allowing the transformation of bending stress distribution measured across gear root into contact stress distribution over tooth flank has been developed,

- finite element analysis of a gear tooth to investigate its behaviour under certain load conditions have been performed,

- a bespoke test rig as a verification point of computer simulations has been designed and manufactured.

This enabled investigation of various load cases and observation of the gear tooth response. The results from the simulation of the gear tooth model have been compared to calculations based on ISO recommendations.

\section{METHODS}

Analysis of the effect of load distribution over the face width, on the contact stress and on the stress at the root, was carried out using the four methods described in the following subsections. Calculations and simulations in all four methods were based on planetary stage gear parameters (sun and a planet)

Table 1. Gear geometry parameters

\begin{tabular}{lcc}
\hline Parameters & Planet gear & Sun gear \\
\hline Normal module $m_{n}[\mathrm{~mm}]$ & 8 & \\
\hline Centre distance $a_{w}[\mathrm{~mm}]$ & 379 & \\
\hline Face width $b_{f}[\mathrm{~mm}]$ & 210 & \\
\hline Pressure angle $a_{n}\left[^{\circ}\right]$ & 25 & 30 \\
\hline Helix angle $\beta\left[^{\circ}\right]$ & 0 & 0.233 \\
\hline Numbers of teeth $z$ & 64 & 261 \\
\hline Profile shift coefficients $x$ & 0.1487 & 0.3 \\
\hline Tip diameter $d_{a}[\mathrm{~mm}]$ & 529.77 & \\
\hline Fillet radius $\rho_{f P}$ & 0.3 &
\end{tabular}

of a 2 MW wind turbine gearbox. The geometry parameters of the gears are shown in Table 1.

For the computer simulations, typical material properties of steel were applied (Young's modulus of $210 \mathrm{GPa}$ and a Poison ratio of 0.3). In each method, the load was applied at the highest point of a single tooth contact.

\subsection{IS0 6336 Guidelines}

Design guidelines provided by ISO 6336-1 [1] express uneven load distribution along the face width as a function of mesh misalignment in the plane of action, taking into account elastic deformations of the gear and housing, as well as bearing clearances and the deviations caused by manufacturing errors. ISO 6336 distinguishes two face load factors; one for contact stress $K_{H \beta}$ and one for tooth root-bending stress $K_{F \beta}$, which are defined as maximum load per unit face width over average load per unit face width relatively for contact and root stress:

$$
K_{H \beta}, K_{F \beta}=\frac{(F / b)_{\max }}{F_{m} / b},
$$

where $(F / b)_{\max }$ is a maximum load per unit face width, and $F_{m} / b$ an average load per unit face width.

There are three different methods contained in the standards, enabling calculation of the face load factors [1]. A comprehensive analysis of all influence factors enables the bending stress distribution over the face width to be determined. Method A is based on strain measurements across a gear root during operation at working temperature. This research focuses on Method A; however, all of the methods give guidelines and requirements for only one of the two factors, whereas the calculation of the second factor is based on the empirical relationship given below [1]:

$$
K_{F \beta}=K_{H \beta}{ }^{N_{F}},
$$

where the influential factor is described as [1]:

$$
N_{F}=\frac{(b / h)^{2}}{1+b / h+(b / h)^{2}} .
$$

As shown in Eq. (3), the empirical relationship between the face load factors $K_{F \beta}$ and $K_{H \beta}$ is based on the face width to tooth height ratio $(b / h)$. For condition $b / h<3$, it is recommended to substitute $b / h=3$ [1].

\subsection{Thin Slice Model}

In recent times, more and more engineering calculations are being conducted with the use of computer-aided engineering (CAE) tools. To 
investigate the load distribution along face width, the tooth was divided on a finite number of constant width elements as pictured in Fig. 1. The operation allowed investigating the load acting on the tooth as some concentrated forces determined by the divisions, in which each force had an impact on an assigned slice of the tooth. Therefore, the tooth needed to be "cut" into an appropriate number of slices. The number of slices has been determined experimentally to obtain satisfactory accuracy with relatively short calculation time.

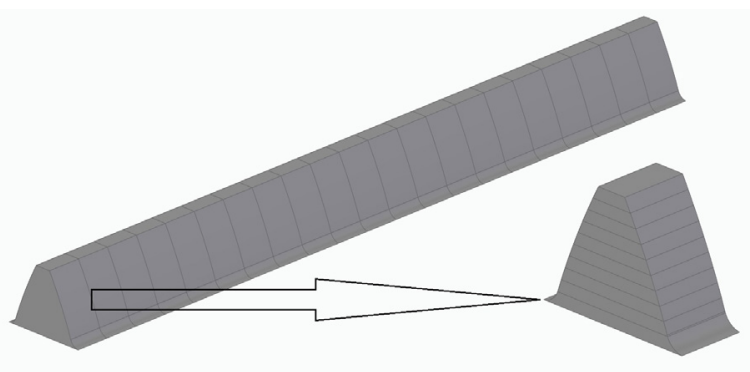

Fig. 1. Visualisation of the thin slice model of a gear tooth

The tooth loaded by a transverse force reacts in a manner similar to a cantilever beam. The deflections of the tooth slices can be expressed as bending combined with shearing. However, an uneven load applied along the face width causes different deflections of the slices. The basic thin slice model assumes a separation between the elements. However, despite the idea that each element is independent of the other elements, an interaction between adjacent elements, known as the coupling effect, is introduced. The difference in displacement between adjacent elements creates a shearing force, acting with the same value on both of the two coupled elements but in opposite directions. While the internal slices are affected by the two neighbouring elements, the two marginal slices can only be supported from inside, exhibiting higher compliance under concentrated load.

The assumptions stated above were taken into account when creating a physical model of the gear tooth. The prepared model shown in Fig. 2 consists of a number of bodies (representing the number of slices) bound together by a set of springs. The stiffness of the elastic elements is described as shearing stiffness between the slices $\left(k_{s s}\right)$, shearing stiffness of the slices $\left(k_{s d}\right)$ and bending stiffness of the slices $\left(k_{b d}\right)$. Each shearing stiffness is calculated taking into account the shearing modulus of the material and the geometry of the elements, Eq. (4) and (5). Bending stiffness is calculated according to the Euler-Bernoulli beam theory, Eq. (6). The shearing force, Eq. (7), acts on each element from both sides apart from the first and the last element. The first and last slice is connected to only one neighbouring slice, as shown in Eqs. (8) and (9).

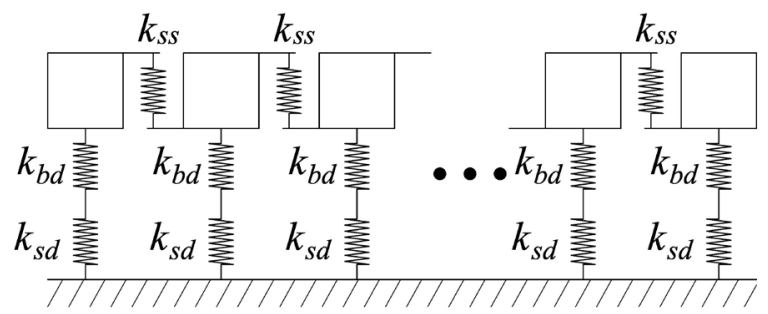

Fig. 2. Physical model of a gear tooth

$$
\begin{gathered}
k_{s s}=\frac{G \times\left(\frac{b}{n s} \times \frac{h}{n d}\right)}{\frac{b}{n s}}, \\
k_{s b}=\frac{G \times\left(s_{i} \times \frac{h}{n d}\right)}{\frac{h}{n d}}, \\
k_{b d}=\frac{3 \times E \times I}{\left(\frac{h}{n d}\right)^{3}}, \\
F_{s i}=\left(y_{i-1}-y_{i}\right) \times k_{s s}+\left(y_{i+1}-y_{i}\right) \times k_{s s}, \\
F_{s 1}=\left(y_{2}-y_{1}\right) \times k_{s s}, \\
F_{s n s}=\left(y_{n s-1}-y_{n s}\right) \times k_{s s},
\end{gathered}
$$

where $G$ is shear modulus, $b$ gear face width, $h$ tooth depth, $s_{i}$ thickness of $i^{\text {th }}$ tooth division, $E$ Young's modulus, $I$ area moment of inertia of the cross-section, $F_{s i} i^{\text {th }}$ shearing force, $y_{i}$ the displacement of the $i^{\text {th }}$ slice, nd the number of tooth divisions, and $n s$ the number of slices.

The effective compliance of one separate slice (without taking into consideration the relationship between the slices) is then:

$$
c_{e}=\frac{k_{b d}+k_{s d}}{k_{b d} \times k_{s d}} .
$$

Gear mesh analysis has been conducted in [28], in which the overall stiffness of a tooth was separated into three major components:

- $\quad$ stiffness of the gear body,

- bending stiffness of the teeth,

- stiffness of the teeth mesh.

For this work, the base rotation and meshing teeth contact deflections were neglected. Investigation 
of the face load factors with the use of the thin slice theory was based only on tooth bending and shearing effects. The simplifications facilitated understanding of basic tooth response to certain load conditions.

A mathematical model based on the physical interpretation shown in Fig. 2 was created in MATLAB software. To obtain an approximate representation of a gear tooth cross-section, each slice was divided on a finite number of beams which stack upon each other. Consequently, the tooth discretization was conducted not only along the face width but also within the slices, as shown in Fig. 1. Additionally, a variable cross-section of stacked beams, and the effective stiffness between the slices, results in a more accurate coupling effect.

The obtained model of gear tooth can be used as a tool in direct calculation of root stress distribution based on face load distribution (design stage of gears), but also in the bottom-up calculation of face load distribution (measurement and diagnostics). A bottom-up approach means that the data extracted from root strain measurement is used as a target in the computations. The initial contact stress distribution is assumed and, after each iteration, the load acting on the gear is adjusted to obtain the desired root stress distribution.

\subsection{Finite Element Analysis}

The tooth shape of the investigated gear was taken directly from an existing design of a planetary gearbox from a $2 \mathrm{MW}$ wind turbine (Table 1). The drawings, including undercuts and tooth modifications, provide an accurate reproduction of the tooth profile. The FEA was performed using CAE Abaqus software. FEA enabled verification of the results from the thin slice model.

An analysis of gear tooth stiffness in [29] presents difficulties and recommendations for reliable FEA, in which factors such as gear body rim thickness or contact positions were examined. Observations from the literature helped in the determination of assumptions and boundary conditions in 3D modelling. The load was applied at the highest point of single tooth contact, and the model is fixed at the surface separating the segment from the rest of the gear body.

The omnipresent problem of FEA modelling is the complexity of the model, which impacts the credibility of the results. Since an analysis of the entire gear is not the focus of the investigation, it has been decided to separate a single tooth with two adjacent fillets, as shown in Fig. 3. The gear mesh was created with two types of hexagonal elements. The mesh in the close vicinity of the tooth root, and the tooth itself was shaped using a structured technique, whereas the rest of the gear body was created with a sweep technique. To maintain the high reliability of the results without involving a high overall number of elements, the created mesh features variable mesh size with smaller elements in the area around gear roots. The structural and relatively uniform shape of the elements across the tooth width was crucial in terms of analysis of the stress distribution. The aforementioned practices avoided stress concentration on irregular shapes.

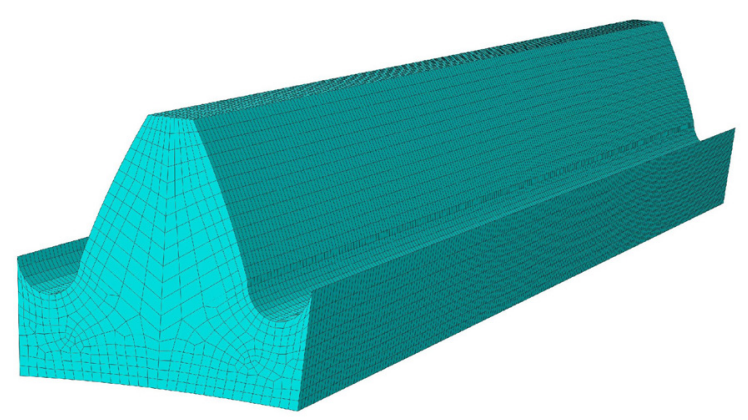

Fig. 3. FE model of the gear tooth

\subsection{Test Rig}

For this work, it was decided to perform a static simulation of the gear tooth behaviour under strictly controlled conditions. A need to validate computer simulations led to the creation of a test rig that, with the use of precise strain measurement system, enabled analysis of the response of the tooth to various load conditions. Moreover, the rig provided an opportunity to analyse undistorted results, taking into account all mechanical properties of the material.

Although real gear mesh conditions require the presence of two mating gears, which was not a case of the investigation, a known load was applied across gear face width as a number of concentrated forces. As in real cases, the most severe (with regard to the tooth root) load conditions could be recorded at the highest point of single tooth contact, thereby creating the highest possible bending moment in the tooth root during gear mesh. As described in the ISO standards, the highest bending stress should be observed in the critical cross-section of a tooth $\left(s_{F n}\right)$, as shown in Fig. 4 , where the load is applied on the bending moment arm, $h_{F e}$, at the angle $\alpha_{F e n}$. However, in real cases, measurement of the root stress in the critical section could cause an interaction of the installed gauges with a mating wheel. 


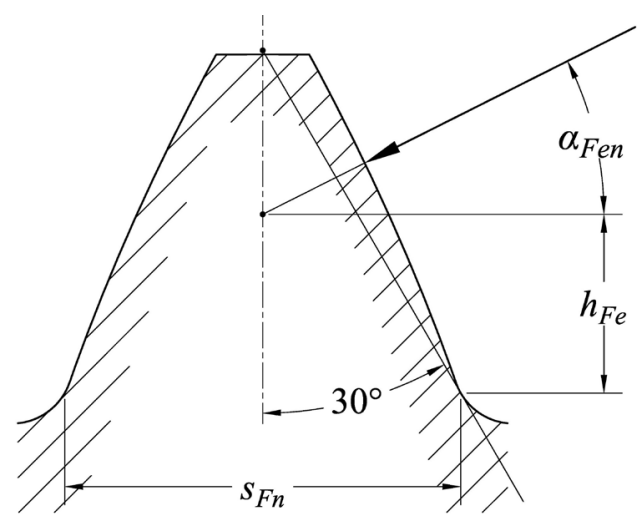

Fig. 4. Critical section of a tooth root

Therefore, to maintain similarity between conditions of real working gearboxes and the designed test bench, strain was measured in the middle between two adjacent teeth. The concentrated forces were applied mechanically through a number of pushrods, which were also strain gauged to measure the applied load. The load was applied, as shown in Fig. 4 , perpendicularly to the tooth surface.

As shown in Fig. 5 a test bench was created as a part of an existing planet gear from the planetary gearbox of 2 MW wind turbine (Table 1). The measured tooth was separated from unwanted, random loads by including additional teeth and extending the bench length. To record higher compliance of the tooth, the tested gear was machined from an aluminium alloy block.

The resulting number of strain gauges installed across the two gear roots and on each of the push-rods, and desired high quality of measurements, required using a bespoke large-channel-count data acquisition system (DAS) that was developed to support the task. The system used a state-of-the-art 32-bit analogue-to- digital converter (ADC) combined with 33 differential multiplied inputs. The fact that the system generates inconsiderable noise is notable. The recorded signal is subjected to a $0.2 \%$ error related to the range of the measurements. To obtain the desired resolution of load intensity distribution, 13 strain gauges were installed in the tensile and compressive root (26 gauges in total). The load was applied via seven pushrods instrumented with strain gauges, each completed in a full Wheatstone bridge to measure directly the load applied to the flank.

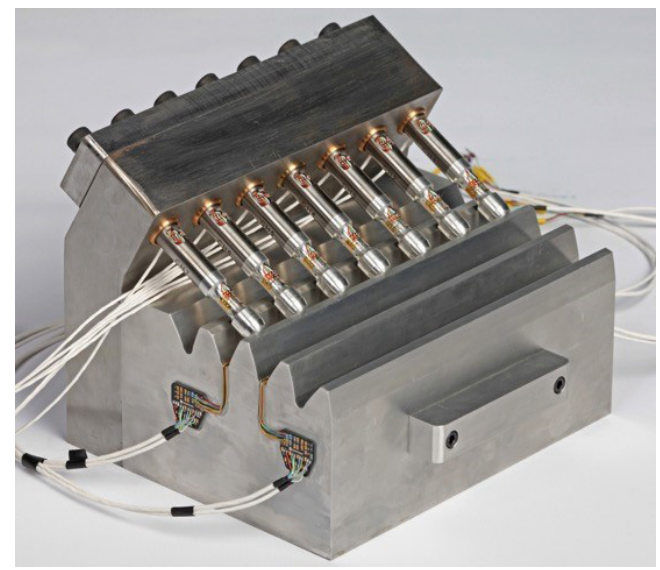

Fig. 5. Test rig

The load was applied via tightening the bolts located in the steel support. The tip of the bolt contacts the push-rod, which transfers load directly to the surface of the tooth. The DAS receives voltage signals from the seven push-rods and the 26 installed gauges. The values of change in voltage are then displayed in computer software, as shown in Fig. 6. Channels 1 to 7 are assigned to the seven push-rods. Channels 8 to 20 are assigned to the non-driving flank, whereas

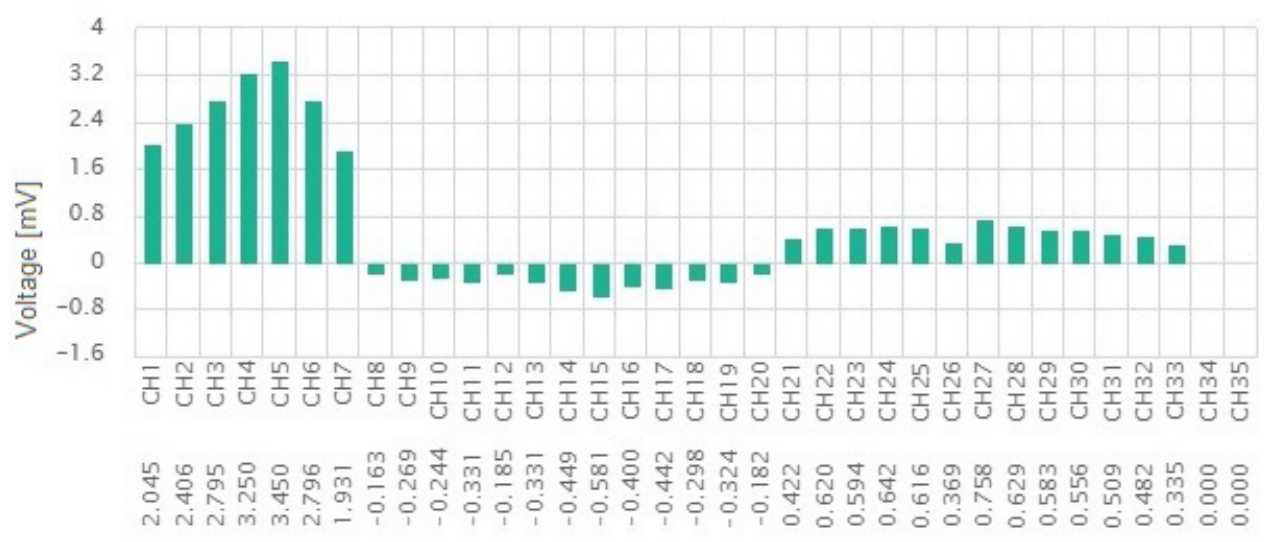

Fig. 6. Test rig measurements 
channels 21 to 33 are assigned to the driving flank of the tooth.

The obtained values of change in voltage are then converted into strain, in accordance with the rules of strain measurements Eq. (11) and (12), and then into stress, in accordance with Hooke's law (Eq. (13)).

$$
\frac{\Delta R}{R}=k \times \varepsilon,
$$

where $R$ is a resistance of strain gauge, $k$ gauge factor, and $\varepsilon$ strain, and the measured voltage takes the form:

$$
U_{A}=\frac{R_{1} \times R_{3}-R_{2} \times R_{4}}{\left(R_{1} \times R_{2}\right) \times\left(R_{3} \times R_{4}\right)} \times U_{E},
$$

where $R_{i}$ is a resistance of strain gauge $(i=1,2,3,4)$, $U_{A}$ measured voltage, and $U_{E}$ excitation voltage:

$$
\sigma=E \times \varepsilon,
$$

where $\sigma$ is stress, $E$ Young's modulus, and $\varepsilon$ strain.

The advanced telemetry system developed by Transmission Dynamics Ltd. combined with principle mathematical formulas enabled measurement of stress at the bottom of the gear root caused by the applied load.

\section{RESULTS}

The four methods of analysis of the relationship between face load distribution described in the previous chapter present a diverse approach to the problem. It was decided to compare the methods against each other, allowing the finding of compatibilities and irregularities occurring between them.

\subsection{Comparative Analysis of the Methods}

Comparison of the methods was based on tooth response analysis to three special load cases, which were unique for normal gear operation. Every load, its type, and location, applied directly to the tooth flank, causes relative bending stress specific to each case distributed across the gear root. Stress outputs were taken from the driving flank of the tooth, matched and related to the common mean value to provide valuable analyses.

One of the load cases was the force concentrated near the edge of the gear tooth. The applied load causes non-uniform stress intensity distribution across the gear root shown in Fig. 7, in which the blue line shows FEA results, the red line shows thin slice results, and the dots show the test bench measurements. The horizontal axis of the graph describes the position on the gear face with and the vertical axis describes the dimensionless value of tensile stress over the mean tensile stress ratio. The mean value $\sigma_{\text {mean }}$ is calculated, taking into account results from each load case and for each method. The results show the occurrence of the highest stress under the applied load. Relative stress intensity decreases towards the opposite end of the tooth, finally reaching zero. Differences between the methods are seen in the values of relative stress in the area of the applied load. They result from simplifying assumptions applied in the thin slice model. It is also noticeable that the thin slice plot features discontinuity in the point of applied load due to imperfections in coupling reaction between the slices. However, the overall shape of the curves indicates a convergence of the methods.

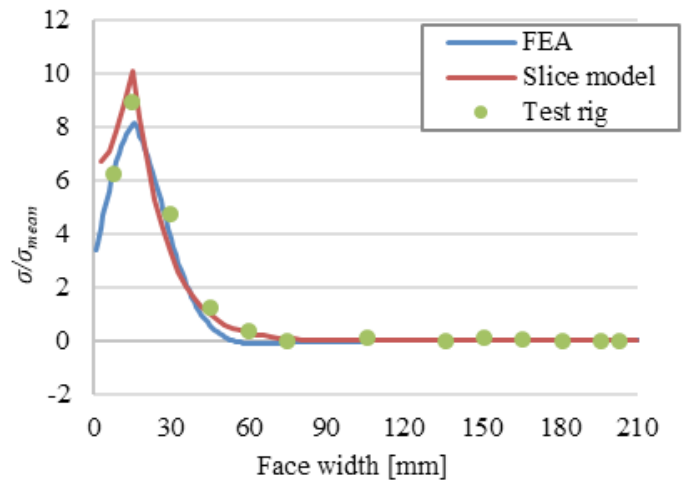

Fig. 7. Response to load applied next to the gear edge

The second load case, i.e., load concentrated in the middle of face width, is shown in Fig. 8. The load causes symmetric tooth deflections and relative root stress decreasing towards the edges of the tooth in each of the methods.

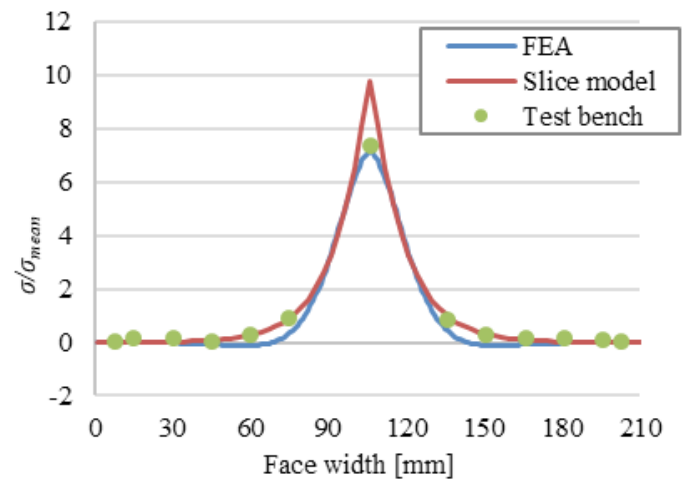

Fig. 8. Response to load applied in the middle of face width

A closer comparison between the two load cases reveals an interesting feature of the gear tooth. 
The results shown in Figs. 7 and 8 indicate higher tooth compliance closer to the edge. The above phenomenon is a result of the coupling effect, which binds together the adjacent cross-sections of the gear tooth. Because the boundary conditions at the edges of face width determine zero coupling forces, the higher tooth deflections cause larger bending stress in the gear root. In both cases, the thin slice model features discontinuity of the stress curve appearing on the loaded slice. This minor drawback disrupts the results, but should not play a significant role in more realistic load cases.

The third load case investigates the response of the tooth to uniformly distributed load across the face width. The relative bending stress distribution is shown in Fig. 9. In this case, uniform load causes a discrepancy in the results. Equal force acting on each of the elements in thin slice model causes equal deflection along the face width, as a result, eliminating coupling forces between the slices.

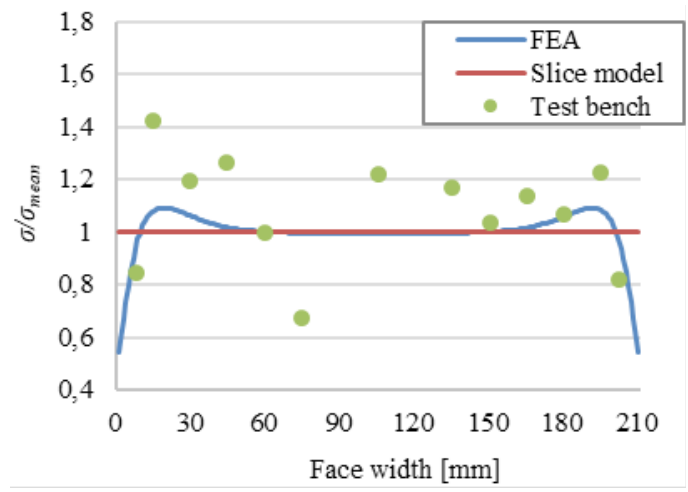

Fig. 9. Response to uniform load

Measurements made on the test bench show disrupted results. In the central part of the gear face width, one of the measurements differs significantly from the others. Inspection of the bench revealed an air bubble just below a strain gauge disrupting the measurements. In addition, it is recommended to perform gauge sensitivity analysis to their deviation from the centre of the gear root. Another noticeable disruption in the side regions is caused by discontinuous load application by seven push rods spaced $30 \mathrm{~mm}$ apart, explaining the alternating readings. However, interesting behaviour can be seen at the very edge of the tooth where the relative stress suddenly increases to the highest value and gradually decreases towards the middle of the tooth. The phenomenon repeats in FEA results on both sides of the tooth. Despite the high dispersion of probe values, an overall trend seems to match the FEA outcome. Additional experiments in FEA revealed the strong influence of Poisson's ratio on the edge effect. However, because the middle section of a tooth is heavily constrained, the effect is only noticeable at the tooth edges pushing the material further and causing higher root bending stress.

\subsection{Relative Stress Intensity Distribution Measured on Existing Gear Set}

The previous subsection dealt with comparison of the results from three methods in terms of three load cases, whereas the present section shows the relationship between the two face load factors, $K_{H \beta}$ and $K_{F \beta}$, obtained from the thin slice method and in accordance to ISO 6336-1 [1] recommendations.

As an input to the calculations, the relative stress distribution was measured across the existing gear root of the $2 \mathrm{MW}$ gearbox, whereas the aim was to convert the obtained face load factor for tooth root stress $K_{F \beta}$ into face load factor for contact stress $K_{H \beta}$ using both methods. Fig. 10 shows blue and red curves representing the face load distribution of bending stress and calculated face load distribution of contact stress, respectively. The face load factor $K_{F \beta}$, the same for both methods, was calculated from given root stress values according to Eq. (1).

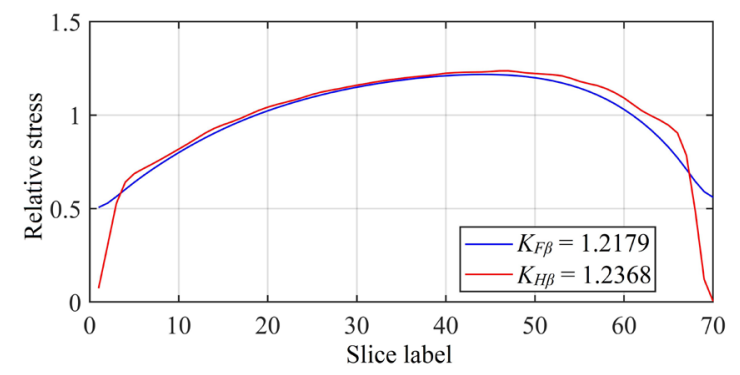

Fig. 10. Thin slice calculations

In this particular case: $K_{F \beta}=1.2197$.

Face load factor $K_{H \beta}$ was calculated according to ISO 6336-1 [1] recommendations using Eq. (2) and (3): $K_{H \beta-I S O}=1.2412$.

Whereas face load factor $K_{H \beta}$ was calculated with the thin slice model: $K_{H \beta}=1.2368$.

The relative percentage error of the thin slice method for this particular load case is then: $\delta=0.36 \%$. 


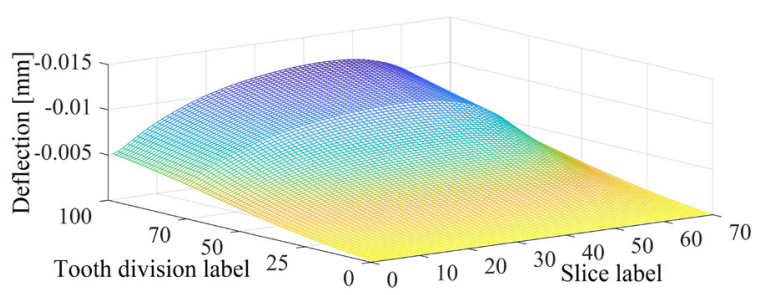

Fig. 11. Deflection in the physical model of gear tooth

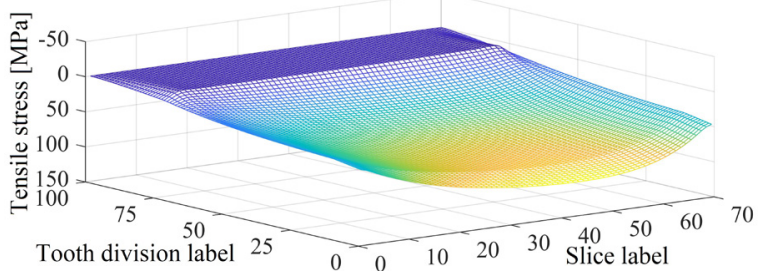

Fig. 12. Tensile stress due to bending

Deflections and the tensile stress of a gear tooth calculated by using the thin slice model are shown in Figs. 11 and 12, in which the load is determined from gear root strain measurements as in the above test. The obtained deflections and tensile stress are plotted for any element of the model, with 70 slices and 100 elements within the slices.

The above test confirms the success of the development of the thin slice model as a reliable tool for the determination of relative contact-stressintensity distribution based on strain measurements across the gear root, despite minor deviations revealed previously in the extreme load cases.

\section{DISCUSSION}

Analysis of unique tooth behaviour under various extreme load cases covered in subsection 2.1 helped in defining features having an impact on the relationship between face load factors for contact and bending stress. Two major phenomena have been observed: the edge effect and the coupling effect.

The idea of coupling is to provide an interaction between two or more elements. Any deflections of the tooth are transmitted across the face width by shearing forces, locally sharing the load. As simulated in the thin slice model, the coupling effect binds two adjacent elements together distributing the load between the closest slices. This feature directly affects the relationship between stress intensity distribution on the tooth flank and in the tooth root. The strength of the coupling effect refers to the magnitude of shearing force, which depends on the material properties and size of gear tooth cross-section in the transverse plane (mainly its height).
The edge effect, observed in the analysis of tooth response to uniform load, is largely dependent on the material properties of which the gear was made. The described phenomenon relates to stress concentration areas next to the tooth edges due to the influence of the Poisson effect. Unsurprisingly, both FEA and test rig measurements featured similar response to uniformly distributed load. The FEA analysis helped to understand the causes of the effect by changing the value of Poisson's ratio of the material. The values close to zero caused the disappearance of the edge effect. Narrow gears can be affected more by the edge effect because of its greater contribution to overall stress intensity distribution.

Growing requirements to improve gear reliability entails the need to develop methods of gear modelling, especially the ends of the teeth. Higher compliance of the gear tooth around its edge is likely to have a significant influence on the load distribution along the line of contact.

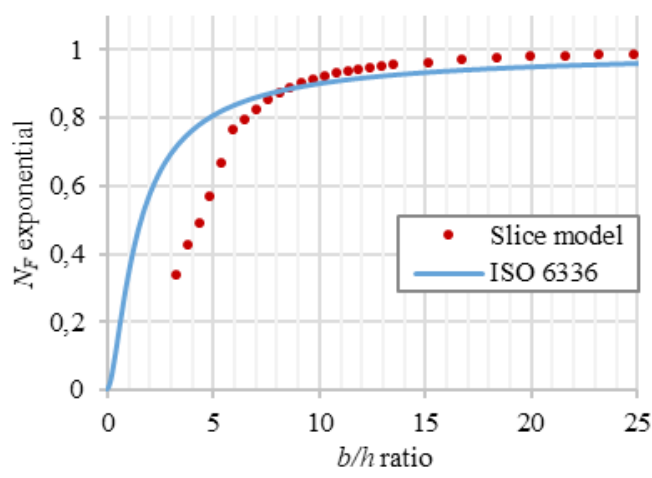

Fig. 13. Convergence of $K_{F \beta}$ and $K_{H \beta}$ factors

Recommendations contained in ISO 6336-1 [1] concerning the relationship between $K_{F \beta}$ and $K_{H \beta}$ factors tend to confirm the validity of the above observations. According to Eqs. (2) and (3), the principle of the relationship is $b / h$ ratio. As shown in Fig. 13, the coincidence of the face load factors grows asymptotically with the $b / h$ ratio, which is consistent with the observations. A simple formula provided by ISO 6336-1 describes the relationship between the two face load factors. The plot shows that results from thin slice calculations also tend to grow asymptotically with the $b / h$ ratio. However, the obtained values of $N_{F}$ exponential differ from ISO guidelines, especially for $b / h<7$. The above observations show the need for further analysis between the face load factors and possible modification of the formula given in ISO 6336-1 [1]. 


\section{CONCLUSIONS}

A thin slice model has successfully been developed; it allows a reliable correlation to be established between $K_{F \beta}$ and $K_{H \beta}$ factors. Validation of the model has been performed based on ISO 6336-1 recommendations, confirming the compatibility of the methods. A comparative analysis of the methods investigating root stress distribution under various load cases gave a satisfactory response of the thin slice model concerning the coupling effect. However, further development should be done to incorporate the sensitivity of the tool to edge effect and eliminate the discontinuity revealed in the extreme load cases.

The bespoke designed test rig enabled the determination of the relative stress intensity distribution by direct strain measurements in gear roots. Test rig measurements were carried out in controlled load conditions with the use of specialized instrumentation and developed software. Determination of face load factors is based on Method A specified in ISO 6336 standards (measurements by strain gauging). The test rig provides a point of reference for other methods; however, one should be aware of measurement error due to strain gauge positioning. Additional research indicates the high sensitivity of the gauge output to the accuracy of its positioning. It is recommended to perform strain gauge calibration to ensure compliance of measurements with the actual stress conditions.

The thin slice model confirmed that the coupling effect was related to the shearing forces between the slices, closely following the relationship between face load factors described in ISO 6336-1. The coupling effect represents a tendency of the gear tooth to transmit deflections across face width. Investigation of the feature shows the influence of material properties and tooth cross-section sizes on the magnitude of the effect. ISO guidelines provide formulas regarding the correlation between face load factors only for gears made of steel.

The edge effect, associated with Poisson's ratio, affects bending stress distribution and tooth deflections in the area around tooth edges. The results from FEA and test rig measurements confirm the suppositions. Concerning the middle section of gear face width as highly constrained, the Poisson effect has no noticeable impact on tooth deflections. The influence of this feature on the coincidence of the face load factors decreases for wider gears. The edge effect is unprecedented in the available literature, which prompts further study of the observed problem.

\section{NOMENCLATURES}

$b$ gear face width, [mm]

$c_{e}$ effective compliance of a slice, $[\mathrm{mm} / \mathrm{N}]$

$E \quad$ Young's modulus, [Pa]

$F \quad$ load applied to a tooth, [N]

$G$ shear modulus, [Pa]

$F_{m}$ average load applied to a tooth, [N]

$F_{s i} i^{\text {th }}$ shearing force, $[\mathrm{N}]$

$h$ tooth depth, [mm]

$h_{\mathrm{Fe}}$ bending moment arm, [mm]

I area moment of inertia, $\left[\mathrm{mm}^{4}\right]$

$k$ gauge factor, [-]

$k_{b d}$ bending stiffness, [N/mm]

$k_{s d}$ shearing stiffness of a slice, [N/mm]

$k_{s s}$ shearing stiffness between slices, [N/mm]

$K_{H \beta}$ face load factor for contact stress, [-]

$K_{F \beta}$ face load factor for bending stress, [-]

nd number of tooth divisions, [-]

ns number of slices, [-]

$N_{F}$ exponential used in Eq. 2, [-]

$R$ resistance of a strain gauge, $[\Omega]$

$s_{F n}$ tooth root chord at the critical section, [mm]

$s_{i} \quad$ thickness of $i^{\text {th }}$ tooth division, [mm]

$U_{A}$ measured voltage, [V]

$U_{E}$ excitation voltage, [V]

$y_{i}$ displacement of $\mathrm{i}^{\text {th }}$ slice, $[\mathrm{mm}]$

$\alpha_{F e n}$ load direction angle, [rad]

$\delta$ relative percentage error, [\%]

$\varepsilon \quad$ strain, [-]

$\rho_{F}$ tooth root radius at the critical section, $[\mathrm{mm}]$

$\sigma \quad$ stress, $[\mathrm{MPa}]$

$\sigma_{\text {mean }}$ mean stress, $[\mathrm{MPa}]$

\section{REFERENCES}

[1] ISO 6336-1:2006. Calculation of load capacity of spur and helical gears. Part 1: Basic principles, introduction and general influence factors. International Organization for Standardization, Geneva.

[2] IS0 6336-2:2006. Calculation of load capacity of spur and helical gears. Part 2: Calculation of surface durability (pitting). International Organization for Standardization, Geneva.

[3] ISO 6336-3:2006. Calculation of load capacity of spur and helical gears. Part 3: Calculation of tooth bending strength. International Organization for Standardization, Geneva.

[4] Yong-tao, T., Cong-xin, L., Wei, T., Chang-hua, W. (2003). A finite-element-based study of the load distribution of a heavily loaded spur gear system with effects of transmission shafts and gear blanks. Journal of Mechanical Design, vol. 125, no. 3, p. 625-631, DOI:10.1115/1.1584689.

[5] Chang L., Liu G., Wu L. (2015). A robust model for determining the mesh stiffness of cylindrical gears. Mechanism and Machine Theory, vol. 87, p. 93-114, D0l:10.1016/j. mechmachtheory.2014.11.019. 
[6] Lias, M.R., Rao, T.V.V.L.N., Awang, M., Khan, M.A. (2012). The stress distribution of gear tooth due to axial misalignment condition. Journal of Applied Sciences, vol. 12, no. 23, p. 2404-2410, DOl:10.3923/jas.2012.2404.2410.

[7] Kawalec A., Wiktor J., Ceglarek D. (2006). Comparative analysis of tooth-root strength using ISO and AGMA standards in spur and helical gears with FEM-based verification. Journal of Mechanical Design, vol. 128, no. 5, p. 1141-1158, Dol:10.1115/1.2214735.

[8] Lise, T.J., Shaw, B.A., Frazer, R.C. (2017). External spur gear root bending stress: A comparison of ISO 6336:2006, AGMA 2101-D04, ANSYS finite element analysis and strain gauge techniques. Mechanism and Machine Theory, vol. 111, p. 1-9, D0I:10.1016/j.mechmachtheory.2017.01.006.

[9] Pisula, J., Budzik, G., Przeszłowski, Ł. (2019). An analysis of the surface geometric structure and geometric accuracy of cylindrical gear teeth manufactured with the direct metal laser sintering (DMLS) method. Strojniški vestnik Journal of Mechanical Engineering, vol. 65, no. 2, p. 78-86, DOI:10.5545/sv-jme.2018.5614.

[10] Zeng, Q.L., Wang, K., Wan, L.R. (2018). Modelling of straight bevel gear transmission and simulation of its meshing performance. International Journal of Simulation Modelling, vol. 17, no. 3, p. 521-533, D0l:10.2507/IJSIMM17(3)C012.

[11] Zeng, Q.L., Wang, K., Wan, L.R., Zhang, X. (2017). Accurate modelling and transient meshing analysis of involute spur gear based on the principle of gear shaping. International Journal of Simulation Modelling, vol. 16, no. 2, p. 322-333, DOI:10.2507/IJSIMM16(2)C07.

[12] Peng, Y., Zhao, N., Qiu, P., Zhang, M., Li, W., Zhou, R. (2018). An efficient model of load distribution for helical gears with modification and misalignment. Mechanism and Machine Theory, vol. 121, p. 151-168, D0l:10.1016/j. mechmachtheory.2017.10.019.

[13] Zhou, C., Chen, C., Gui, L., Fan, Z. (2018). A nonlinear multipoint meshing model of spur gears for determining the face load factor. Mechanism and Machine Theory, vol. 126, p. 210224, D0I:10.1016/j.mechmachtheory.2018.04.010.

[14] Li, X.Y., Wang, N. N., Lv, Y. G., Zeng, Q.L., Hidenori, K. (2016). Tooth profile modification and simulation analysis of involute spur gear. International Journal of Simulation Modelling, vol. 15, no. 4, p. 649-662, D0I:10.2507/IJSIMM15(4)6.358.

[15] Wang, G., Su, L., Zou, S. (2020). Uneven load contact dynamic modelling and transmission error analysis of a $2 \mathrm{~K}-\mathrm{V}$ reducer with eccentricity excitation. Strojniški vestnik Journal of Mechanical Engineering, vol. 66, no. 2, p. 91-104, DOI:10.5545/sv-jme.2019.6298.

[16] Krawiec, S., Krawiec, M., Leśniewski, T. (2017). Correlation of gears strength and methods of determining the coefficient of load distribution along the tooth width. Lecture Notes in Mechanical Engineering. Proceedings of the 13th International Scientific Conference: Computer Aided Engineering, p. 275284, D0l:10.1007/978-3-319-50938-9_28.

[17] Wang, Q., Zhao, B., Fu, Y., Kon,g X., Ma, H. (2018). An improved time-varying mesh stiffness model for helical gear pairs considering axial mesh force component. Mechanical Systems and Signal Processing, vol. 106, p. 413-429, D0l:10.1016/j. ymssp.2018.01.012.

[18] Haigh, J., Fawcett, J.N. (2003). Effects of misalignment on load distribution in large face-width helical gears. Proceedings of the Institution of Mechanical Engineers, Part K: Journal of Multi-body Dynamics, vol. 217, no. 2, p. 93-98, DOI:10.1243/146441903321898584.

[19] Pedrero, J.I., Pleguezuelos, M., Artes, M., Antona, J.A. (2010). Load distribution model along the line of contact for involute external gears. Mechanism and Machine Theory, vol. 45, no. 5, p. 780-794, D0l:10.1016/j.mechmachtheory.2009.12.009.

[20] Guilbault, R., Gosselin, C., Cloutier, L. (2005). Express model for load sharing and stress analysis in helical gears. Journal of Mechanical Design, vol. 127, no. 6, p. 1161-1172, DOl:10.1115/1.1992509.

[21] Ajmi, M., Velex, P. (2005). A model for simulating the quasistatic and dynamic behaviour of solid wide-spaced spur and helical gears. Mechanism and Machine Theory, vol. 40, no. 2, p. 173-190, D0I:10.1016/j.mechmachtheory.2003.06.001.

[22] Hotait, M., Kahraman, A. (2008). Experiments on root stresses of helical gears with lead crown and misalignments. Journal of Mechanical Design, vol. 130, no. 7, p. 074502, DOI:10.1115/1.2931127.

[23] Wang, N., Li, X., Wang, K., Zeng, Q., Shen, X. (2017). A novel axial modification and simulation analysis of involute spur gear. Strojniški vestnik - Journal of Mechanical Engineering, vol. 63, no. 12, p. 736-745, D0l:10.5545/sv-jme.2017.4307.

[24] Daffner, M., Otto, M., Stahl, K. (2017). Method of measuring the load distribution of spur gear stages. Journal of Advanced Mechanical Design Systems and Manufacturing, vol. 11, no. 6, p. 1-10, D0I:10.1299/jamdsm.2017jamdsm0076.

[25] Meeusen W., Ceulemans W., Otto M. (2010). Load Distribution Measurements on Planetary Gear Systems - Experimental verification of the face load factor for contact stress, $\mathrm{K}_{\mathrm{H} \beta}$, and mesh load factor, $K_{v}$, in planetary gear stages. Proceedings of the $4^{\text {th }}$ International Conference on Gears, Europe invites the world. Munich, p. 697-711.

[26] Kamycki, W. (2016). Investigation of the relationship between the relative stress intensity distribution measured across gear root and face load factor $K_{H b}$. MSc Thesis, Cranfield University, Cranfield.

[27] Kamycki W., Noga S., Batsch M. (2019). Computation verification of the segmental model of dependencies between the factors of $K_{H \beta}$ and $K_{F \beta}$ for spur gears. Scientific Letters of Rzeszów University of Technology 299 Mechanics, vol. 91, no. 1-2, p. 27-39, Dol:10.7862/rm.2019.03. (in Polish)

[28] Kiekbusch T., Sappok D., Sauer B., Howard I. (2011). Calculation of the combined torsional mesh stiffness of spur gears with two- and three-dimensional parametrical FE models. Strojniški vestnik - Journal of Mechanical Engineering, vol. 57, no. 11, p. 810-818, D0l:10.5545/sv-jme.2010.248.

[29] Pedersen N.L., Jørgensen M.F. (2014). On gear tooth stiffness evaluation. Computers and Structures, vol. 135, p. 109-117, DOI:10.1016/j.compstruc.2014.01.023. 